\title{
PP-EPDM thermoplastic vulcanisates (TPVs) by electron induced reactive processing
}

\author{
K. Naskar ${ }^{1,2}$, U. Gohs ${ }^{1}$, U. Wagenknecht ${ }^{1}$, G. Heinrich ${ }^{1}$ \\ ${ }^{1}$ Leibniz-Institut für Polymerforschung Dresden e.V., Hohe Strasse 6, D-01069 Dresden, Germany \\ ${ }^{2}$ Rubber Technology Centre, Indian Institute of Technology, Kharagpur, Kharagpur-721302, West Bengal, India
}

Received 23 June 2009; accepted in revised form 12 August 2009

\begin{abstract}
Reactive processing combines melt mixing process and chemical reaction simultaneously. TPVs are produced by such reactive processing. Polymer modification with high energy electrons is based on generation of excited atoms or molecules and ions for subsequent molecular changes via radical induced chemical reactions. In the present study, electron induced reactive processing is used for the development of TPVs. A $1.5 \mathrm{MeV}$ electron accelerator was directly coupled to an internal mixer in order to induce chemical reactions by energy input via high energy electrons under dynamic conditions of melt mixing of polypropylene (PP) and ethylene propylene diene monomer rubber (EPDM). The influence of absorbed dose (25 to $100 \mathrm{kGy}$ ) as well as electron energy (1.5 and $0.6 \mathrm{MeV})$ and electron treatment time (15 to $60 \mathrm{~s}$ ) have been studied. Increased values of both tensile strength and elongation at break of the TPVs indicate in-situ compatibilisation of PP and EPDM as well as cross-linking in the EPDM phase upon electron induced reactive processing. Dynamic mechanical analyses showed a decrease in value of glass transition temperature peak of EPDM in tangent delta curve with increasing dose. This also indicates higher degree of cross-linking in EPDM phase, which is further supported by a gel content that is higher than the EPDM content itself in the blend.
\end{abstract}

Keywords: polymer blends and alloys, PP, EPDM, thermoplastic vulcanisate, electron induced reactive processing

\section{Introduction}

Thermoplastic elastomers (TPEs) are one of the fastest growing polymeric materials which combine the elastic and mechanical properties of crosslinked rubbers with the melt processability of thermoplastics [1,2]. TPEs find lot of applications in automotives, buildings and constructions, wires and cables, soft touch etc. The most important advantage of a TPE is its ability to reuse and recycle the production scrap and waste. TPVs or dynamic vulcanisates are a special class of TPEs, produced by simultaneously mixing and cross-linking a rubber with a thermoplastic at elevated temperature [3-5]. As a result a typical morphology is formed, where the cross-linked rubber particles are finely dispersed in a continuous matrix of thermo- plastic. TPVs based on blends of PP and EPDM rubber are most significant from a commercial point of view, where the rubber phase is generally cross-linked either by activated phenol formaldehyde resins or by peroxides [6-12]. Besides advantages, both resin and peroxide cross-linking systems have their own limitations. For instance, phenolic resin has a strong tendency to absorb moisture even at ambient temperature and also appear as a dark brown color. On the other hand, peroxide cross-linked TPVs often provide an unpleasant smell or may show a blooming effect. Furthermore, the rate of generation of peroxide radicals at a constant temperature changes as a function of time. These disadvantages of resins and peroxides create a demand for other alternatives. 
Dynamic vulcanisation by electron induced reactive processing is a potential option.

Influence of electron beam (EB) on PP under static conditions is well known in the literature [13-16] and characterises a process where required absorbed dose is applied to form parts (after molding) in solid state and at room temperature. EB cross-linking of EPDM rubber under static conditions is also reported by several authors [17-19]. The absorbed dose controls the energy input per unit of mass as well as the total number of radicals. However, the effects of high energy electrons in PP-EPDM blends under dynamic conditions were not yet explored. Electron induced reactive processing is a novel technique where chemical reactions are induced by spatial and temporal precise energy input via high energy electrons under dynamic conditions of melt mixing. In this novel process, the penetration depth of electrons is limited to a part of mixing volume. The total mixing volume is modified due to the change of polymer mass within the penetration depth of electrons during mixing process. Further, electron treatment time and electron energy do not only control dose rate and penetration depth, respectively. In the novel process, electron treatment time also influences the ratio of radical generation rate to mixing rate (dose per rotation) and electron energy controls the ratio of modified volume to total mixing chamber volume $\left(r_{v o l}\right)$.

Thus, the primary objective of the present investigation is to develop PP-EPDM based TPVs at 50:50 blend ratio under various conditions (absorbed dose, electron treatment time and electron energy) of electron induced reactive processing. The mechanical, thermal, dynamic mechanical, and morphological characteristics of various dynamically electron cross-linked PP-EPDM blends were pursued to get an in-sight.

\section{Experimental}

\subsection{Materials}

Buna EP G 6850, the ethylidene norbornene (ENB) containing EPDM rubber, was obtained from Lanxess, Leverkusen, Germany. The EPDM contains $51 \mathrm{wt} \%$ of ethylene and $7.7 \mathrm{wt} \%$ of ENB. It has a Mooney viscosity, ML (1+4) at $125^{\circ} \mathrm{C}$ of 60 and a density of $0.860 \mathrm{~g} / \mathrm{cm}^{3}$. PP HD120MO, a polypropylene homopolymer, was obtained from
Borealis, Düsseldorf, Germany. The melt flow rate of the polypropylene, measured at $230^{\circ} \mathrm{C}$ and $2.16 \mathrm{~kg}$, amounts to $8.0 \mathrm{~g} / 10 \mathrm{~min}$. It has a density of $0.908 \mathrm{~g} / \mathrm{cm}^{3}$.

\subsection{Preparation of PP/EPDM TPVs}

All TPVs were prepared by a batch process in a Brabender mixing chamber, having a mixing chamber volume of $50 \mathrm{~cm}^{3}$, with a rotor speed of $45 \mathrm{rpm}$ at $175-180^{\circ} \mathrm{C}$ in presence of air. The friction ratio of the rotors amounts to 1:1.5. Figure 1 shows a schematic representation of the unique set-up. The total time of mixing was 16 min due to safety regulations of electron accelerator. The experimental variables were absorbed dose $(25,50$, and $100 \mathrm{kGy})$, electron treatment time $(15,30$, and $60 \mathrm{~s})$, and electron energy (0.6 and $1.5 \mathrm{MeV})$. Immediately after mixing, the composition was pressed manually by metallic plates without any additional heating to achieve a sheet of about $2 \mathrm{~mm}$ thickness. This sheet was cut into small pieces and pressed in a compression molding machine (Rucks Maschinenbau, Glauchau, Germany) at $200^{\circ} \mathrm{C}$, $6 \mathrm{~min}$, and 88 bar pressure. The sheet was then cooled down to room temperature under pressure. Test specimens were die-cut from the compression molded sheet and used for testing after $24 \mathrm{~h}$ of storage at room temperature.

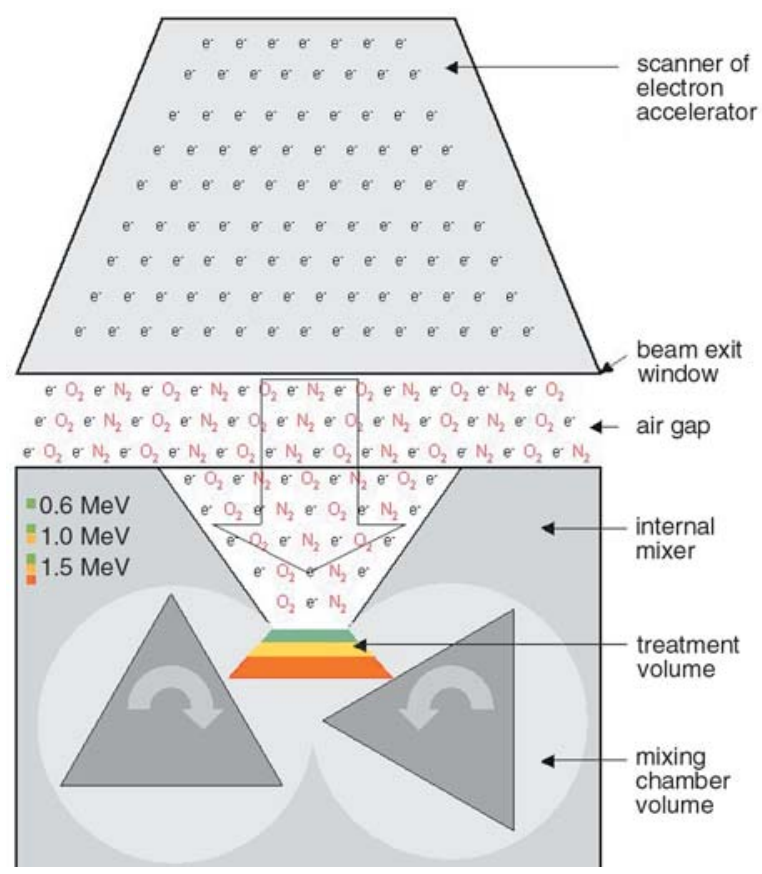

Figure 1. Schematic representation of the set-up: coupling of an electron accelerator with an internal mixer 


\subsection{Testing procedure}

Tensile tests were carried out according to ISO $527-2 / \mathrm{S} 2 / 50$ on dumb-bell shaped specimens using an universal tensile testing machine Zwick 8195.04 at a constant cross-head speed of $50 \mathrm{~mm} / \mathrm{min}$. $E$ modulus was determined in between 0.05 and $0.25 \%$ of strain. Differential scanning calorimeter (DSC) measurements were carried out using a DSC Q1000 (TA instruments, New Castle, USA). The scans were taken in the temperature range from -80 to $200^{\circ} \mathrm{C}$ with a programmed heating rate of $10 \mathrm{~K} / \mathrm{min}$ under $\mathrm{N}_{2}$ atmosphere. Dynamic mechanical thermal analyses (DMTA) of the samples were performed using an Eplexor 2000N DMTA (version $8.373 \mathrm{~h}$ ) at a frequency of $10 \mathrm{~Hz}$ and $0.2 \%$ strain. The samples were first cooled to $-80^{\circ} \mathrm{C}$ and then subsequently heated at a rate of $4 \mathrm{~K} / \mathrm{min}$ over a range of -80 to $140^{\circ} \mathrm{C}$. The $\tan \delta$ peak maxima were assigned to the glass transitions $\left(T_{g}\right)$ of EPDM and PP. Gel content of the samples was calculated after extracting out the PP-phase by boiling xylene. Phase morphology was investigated by a LEO 435 VP Ultra plus Scanning Electron Microscope (SEM) from Carl Zeiss SMT (Jena, Germany) after ultracutting of TPV samples at $-130^{\circ} \mathrm{C}$ in a Leica Ultra-microtome (Wetzlar, Germany).

\section{Results and discussion}

\subsection{Mechanical properties}

Study of mechanical properties of TPVs is very important to understand the effects of electron induced reactive processing. Influence of the various conditions of this novel process on the stressstrain behavior of the PP/EPDM TPVs is shown in Figures $2 \mathrm{a}, \mathrm{b}$, and c. The experimental data of $E$ modulus, tensile strength, and elongation at break as well as and their uncertainties at $96 \%$ confidence level are given in Table 1. From experimental data at $1.5 \mathrm{MeV}$ and for an electron treatment of $60 \mathrm{~s}$ it
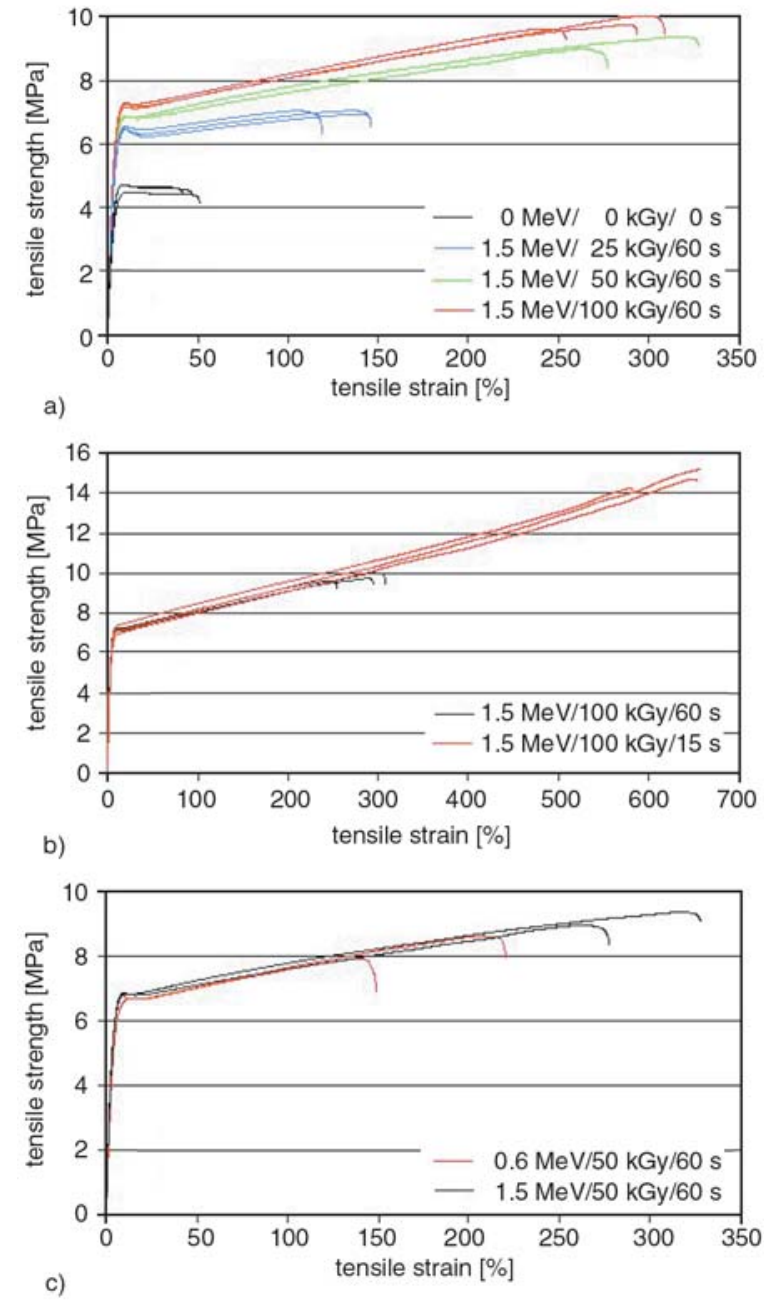

Figure 2. a) Influence of dose on tensile stress as function of tensile strain, b) influence of electron treatment time on tensile stress as function of tensile strain, c) influence of electron energy on tensile stress as function of tensile strain

was observed that with increasing absorbed dose from 25 to $50 \mathrm{kGy}$ tensile strength, elongation at break, and $E$ modulus of the TPVs were significantly improved. In case of the untreated sample tensile strength was only $4.7 \pm 0.1 \mathrm{MPa}$ and elongation at break was $46 \pm 5 \%$. At $50 \mathrm{kGy}$, tensile strength was $9.2 \pm 0.3 \mathrm{MPa}$ and elongation at break

Table 1. Experimental data of $E$ modulus, tensile strength, and elongation at break

\begin{tabular}{|c|c|c|c|c|c|}
\hline $\begin{array}{c}\text { Electron energy } \\
{[\mathrm{MeV}]}\end{array}$ & $\begin{array}{c}\text { Dose } \\
{[\mathrm{kGy}]}\end{array}$ & $\begin{array}{c}\text { Treatment time } \\
{[\mathrm{s}]}\end{array}$ & $\begin{array}{c}\text { E-modulus } \\
\text { [MPa] }\end{array}$ & $\begin{array}{c}\text { Tensile strength } \\
{[\mathrm{MPa}]}\end{array}$ & $\begin{array}{c}\text { Elongation at break } \\
{[\%]}\end{array}$ \\
\hline 0.0 & 0 & 0 & $112 \pm 12$ & $4.7 \pm 0.1$ & $46 \pm 5$ \\
\hline 1.5 & 25 & 60 & $159 \pm 11$ & $7.0 \pm 0.1$ & $135 \pm 15$ \\
\hline 1.5 & 50 & 60 & $156 \pm 4$ & $9.2 \pm 0.3$ & $298 \pm 35$ \\
\hline 1.5 & 100 & 60 & $173 \pm 20$ & $9.8 \pm 0.2$ & $282 \pm 28$ \\
\hline 1.5 & 100 & 30 & $191 \pm 8$ & $9.5 \pm 0.7$ & $215 \pm 80$ \\
\hline 1.5 & 100 & 15 & $176 \pm 3$ & $14.7 \pm 0.5$ & $624 \pm 41$ \\
\hline 0.6 & 50 & 60 & $150 \pm 36$ & $8.2 \pm 0.4$ & $168 \pm 42$ \\
\hline
\end{tabular}


was $298 \pm 35 \%$. Further increase in dose to $100 \mathrm{kGy}$ resulted in a small increase of tensile strength to $9.8 \pm 0.2 \mathrm{MPa}$ where as elongation at break is kept constant $(282 \pm 28 \%)$. Such influence of absorbed dose has been expected from EB treatment under static conditions [19].

The experimental data at $1.5 \mathrm{MeV}$ and $100 \mathrm{kGy}$ showed that with decreasing electron treatment time from $60 \mathrm{~s}(16.5 \mathrm{kGy} / \mathrm{s}$ and $22 \mathrm{kGy}$ per rotation) to $15 \mathrm{~s}$ ( $66 \mathrm{kGy} / \mathrm{s}$ and $88 \mathrm{kGy}$ per rotation), tensile strength and elongation at break were further improved whereas $E$ modulus remained constant at a level of $178 \pm 2 \mathrm{MPa}$. This value is higher in comparison to the $E$ modulus of untreated sample $(112 \pm 12 \mathrm{MPa})$. Highest tensile strength of $14.7 \pm 0.5 \mathrm{MPa}$ and maximum elongation at break of $624 \pm 41 \%$ were recorded for an electron treatment of $15 \mathrm{~s}$. Thus, electron treatment time influencing on dose rate as well as absorbed dose per rotation is an additional parameters controlling the stress-strain behavior of the PP/EPDM TPVs.

The influence of electron energy on mechanical properties was investigated at an absorbed dose of $50 \mathrm{kGy}$ due to limited dose rate of electron accelerator and for an electron treatment time of $60 \mathrm{~s}$. In comparison to the results at $1.5 \mathrm{MeV}(8.2 \mathrm{kGy} / \mathrm{s}$ and $\left.r_{v o l}=0.062\right)$ it is seen that at $0.6 \mathrm{MeV}$ $\left(28.8 \mathrm{kGy} / \mathrm{s}\right.$ and $\left.r_{v o l}=0.017\right)$ tensile strength and elongation at break were reduced whereas $E$ modulus remained constant. Finally, electron energy influencing penetration depth as well as ratio of modified volume to total mixing chamber volume is controlling the stress-strain behavior of the PP/EPDM TPVs.

\subsection{DSC study}

Table 2 shows the experimental data of glass transition temperatures of EPDM and PP $\left(T_{g}\right)$, melting temperature $\left(T_{m}\right)$, crystallisation temperature $\left(T_{c, m}\right)$ and melt enthalpy $(\Delta H)$. The uncertainties of melt enthalpy are related to a confidence level of $96 \%$. Absorbed dose has an influence on both the onset of crystallisation $\left(T_{c, 0}\right)$ and the maximum crystallisation temperature $\left(T_{c, m}\right)$ at fixed electron energy $(1.5 \mathrm{MeV})$ and constant electron treatment time (60 s). For the untreated sample the value of $T_{c, m}$ was $113.5^{\circ} \mathrm{C}$, where as at 25 and $100 \mathrm{kGy}$ the values were increased to 123.1 and $124.8^{\circ} \mathrm{C}$, respectively. This result may be explained by self-nucleation of PP in presence of irradiation, which is in line with the mechanical properties. Further, it was observed that only slight changes took place after EB treatment in the values of $T_{g}$ of EPDM (at around $-53^{\circ} \mathrm{C}$ ) and $\mathrm{PP}$ (at around $-6^{\circ} \mathrm{C}$ ). Furthermore, no significant changes were noticed in enthalpy value $(\Delta H)$ within experimental uncertainty and melting temperature $\left(T_{m}\right)$ of PP after EB treatment indicating hardly any degradation (Table 2).

In contrast to the results of stress-strain behavior, electron treatment time and electron energy have no significant influence on the heat flow curves. Thus, overall orientation, crystallisation, thickness of lamella and crosslinking are not changed.

\subsection{DMTA study}

It can be observed from Figure 3 that storage moduli of all the TPVs were higher than that of the untreated sample over the entire temperature range. Further, storage modulus depends on absorbed dose at fixed electron energy $(1.5 \mathrm{MeV})$ and constant electron treatment time $(60 \mathrm{~s})$. Again, electron treatment time and electron energy have no significant influence on storage modulus of TPVs. Figure 4 illustrates the tan $\delta$ plot as function of temperature and demonstrates that there are two

Table 2. Experimental data of glass transition temperature of EPDM and PP $\left(T_{g}\right)$, melting temperature $\left(T_{m}\right)$, crystallisation temperature $\left(T_{c, m}\right)$, and melt enthalpy $(\Delta H)$

\begin{tabular}{|c|c|c|c|c|c|c|c|}
\hline $\begin{array}{c}\text { Electron } \\
\text { energy } \\
{[\mathrm{MeV}]}\end{array}$ & $\begin{array}{c}\text { Dose } \\
{[\mathrm{kGy}]}\end{array}$ & $\begin{array}{c}\text { Treatment } \\
\text { time } \\
{[\mathrm{s}]}\end{array}$ & $\begin{array}{c}\mathbf{T}_{\mathbf{g}} \\
(\mathbf{E P D M}) \\
{\left[{ }^{\circ} \mathrm{C}\right]}\end{array}$ & $\begin{array}{c}\mathbf{T}_{\mathbf{g}} \\
(\mathbf{P P}) \\
{\left[{ }^{\circ} \mathbf{C}\right]}\end{array}$ & $\begin{array}{c}\mathbf{T}_{\mathrm{m}} \\
\left(2^{\text {nd }} \text { heating) }\right. \\
{\left[{ }^{\circ} \mathrm{C}\right]}\end{array}$ & $\begin{array}{c}\mathrm{T}_{\mathrm{c}, \mathrm{m}} \\
\left(\mathbf{1}^{\mathrm{st}} \text { cooling) }\right. \\
{\left[{ }^{\circ} \mathrm{C}\right]}\end{array}$ & $\begin{array}{c}\Delta H \\
\text { (2nd heating) } \\
{[\mathrm{J} / \mathrm{g}]}\end{array}$ \\
\hline 0.0 & 0 & 0 & -53 & -7 & 158.6 & 113.5 & $50.8 \pm 0.9$ \\
\hline 1.5 & 25 & 60 & -53 & -7 & 161.1 & 123.1 & $49.6 \pm 0.6$ \\
\hline 1.5 & 50 & 60 & -53 & -6 & 160.1 & 124.4 & $48.4 \pm 1.3$ \\
\hline 1.5 & 100 & 60 & -53 & -6 & 158.6 & 124.8 & $51.6 \pm 1.0$ \\
\hline 1.5 & 100 & 30 & -53 & -6 & 158.3 & 125.0 & $51.6 \pm 1.5$ \\
\hline 1.5 & 100 & 15 & -53 & -6 & 158.3 & 124.8 & $51.3 \pm 0.9$ \\
\hline 0.6 & 50 & 60 & -53 & -5 & 160.3 & 124.6 & $49.8 \pm 1.8$ \\
\hline
\end{tabular}




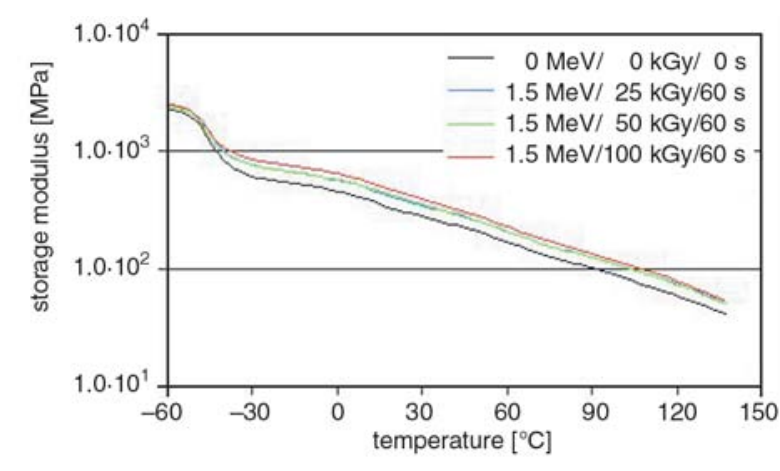

Figure 3. Influence of dose on storage modulus as a function of temperature

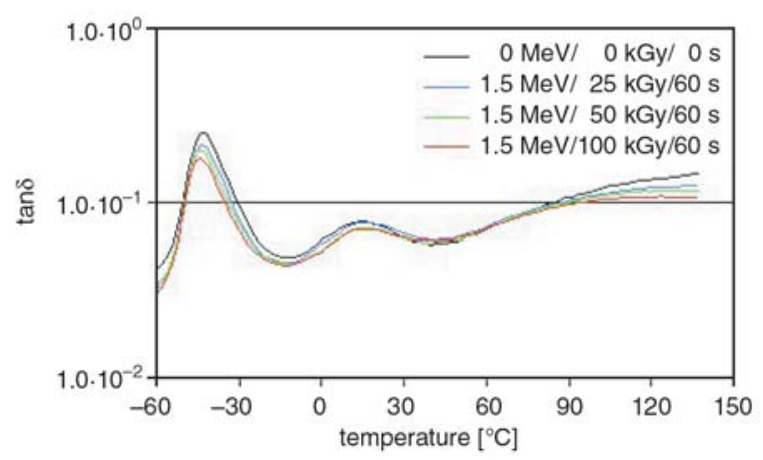

Figure 4. Influence of dose on $\tan \delta$ as a function of temperature

major transitions: the $T_{g}$ of EPDM at around $-43^{\circ} \mathrm{C}$ and that of $\mathrm{PP}$ at around $16^{\circ} \mathrm{C}$. Table 3 shows the $\tan \delta_{\max }$ value at the $T_{g}$ of EPDM of the TPVs at varied absorbed dose. It clearly demonstrates that the values were lowered with increasing absorbed dose indicating higher extent of cross-linking in the EPDM phase and lesser damping characteristics of the TPVs. These results were further supported by the gel content values as also shown in Table 3. With increasing dose the gel content value also increases. The gel content values were higher than the EPDM content itself in the blend which indicated high degree of cross-linking in EPDM phase and the formation of in-situ PP-EPDM graft-links by electron induced reactive processing. The PPEPDM graft-links were not extractable even by boiling xylene and therefore also contribute to the gel contents.
Electron treatment time and electron energy have no significant influence on storage modulus and on the $\tan \delta$ values. Thus, viscous and elastic properties of PP-EPDM TPVs were not changed.

\subsection{Morphology}

TPVs are characterised by its typical dispersed phase morphology, where cross-linked rubber particles are dispersed in a continuous matrix of thermoplastic. In general, the smaller the particle size, the better the mechanical properties. Figures $5 a, b$, and $c$ illustrate SEM photomicrographs of various PP-EPDM blends: both untreated and treated under various conditions. In all cases, a wide distribution of particle sizes is generated due to the mixing under dynamic conditions. It can be seen from the micrographs that for the untreated sample, the particle sizes were much bigger (around $2-3 \mu \mathrm{m}$ ). Electron induced reactive processing at $1.5 \mathrm{MeV}$, $100 \mathrm{kGy}$, and $60 \mathrm{~s}$ results in smaller EPDM particle size (even to $0.2 \mu \mathrm{m}$ ) indicating better dispersion due to the dynamic vulcanisation. The smallest EPDM particle sizes (around $0.04 \mu \mathrm{m}$ ) were recorded in case of $100 \mathrm{kGy}$ absorbed dose and $15 \mathrm{~s}$ electron treatment time (Figure $5 \mathrm{c}$ ) at $1.5 \mathrm{MeV}$, which is in line with the mechanical properties.

\section{Conclusions}

Thermoplastic vulcanisates (TPVs) were prepared by dynamic vulcanisation with 50:50 blend ratio of PP and EPDM using novel electron induced reactive processing under various conditions as an alternative to conventional phenolic resin and peroxide cross-linking systems. The adhesion between the dispersed EPDM particles and PP matrix plays a very important role governing the deformation behavior of the TPVs. It can be concluded that electron induced reactive processing with $1.5 \mathrm{MeV}$ electrons for $15 \mathrm{~s}$ at an absorbed dose of $50 \mathrm{kGy}$ should give best balance of mechanical properties for our experimental setup.

Table 3. $\tan \delta_{\max }$ and gel content of various PP-EPDM TPVs

\begin{tabular}{|c|c|c|c|c|}
\hline Electron energy [MeV] & Dose [kGy] & Treatment time [s] & tan $\boldsymbol{\delta}$ peak value (EPDM) & Gel content [\%] \\
\hline 0.0 & 0 & 0 & 0.249 & 0.0 \\
\hline 1.5 & 25 & 60 & 0.213 & 54.5 \\
\hline 1.5 & 50 & 60 & 0.201 & 64.0 \\
\hline 1.5 & 100 & 60 & 0.180 & 65.0 \\
\hline
\end{tabular}




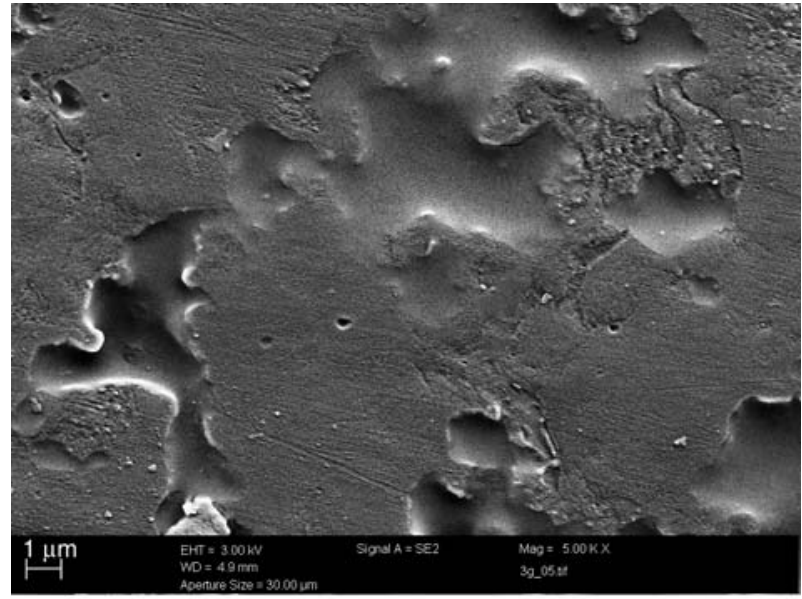

a)

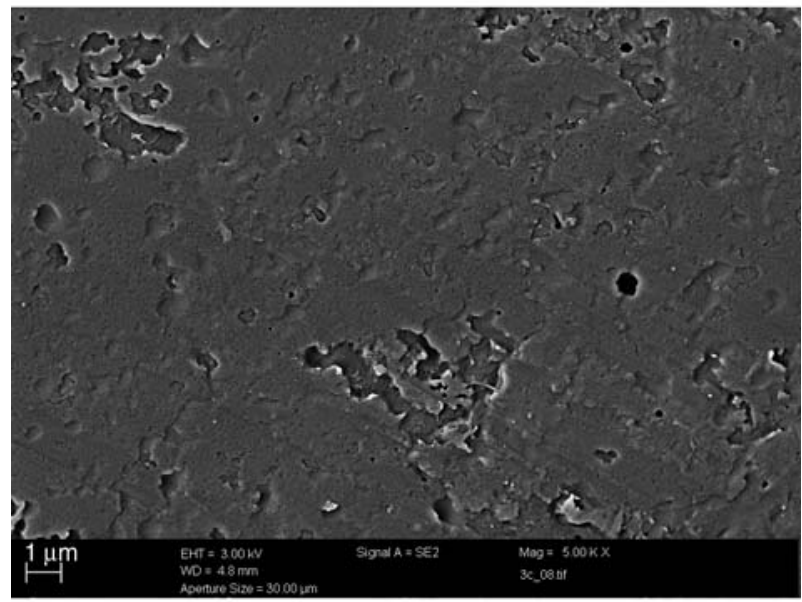

b)

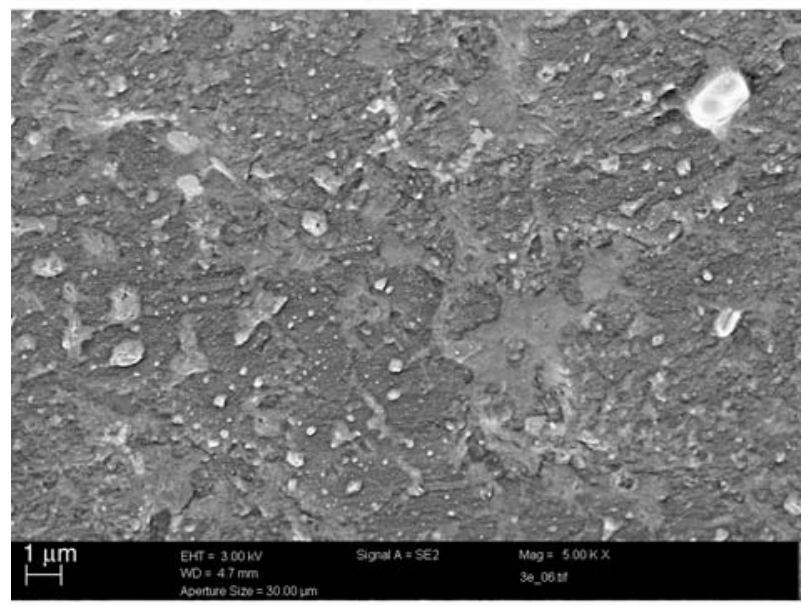

c)

Figure 5. a) SEM photomicrograph of sample: $0 \mathrm{MeV}$, $0 \mathrm{kGy}, \mathrm{b})$ SEM photomicrograph of sample: $1.5 \mathrm{MeV}, 100 \mathrm{kGy}$ for $60 \mathrm{~s}, \mathrm{c})$ SEM photomicrograph of sample: $1.5 \mathrm{MeV}, 100 \mathrm{kGy}$ for $15 \mathrm{~s}$

The experimental results clearly indicated that two processes are simultaneously occurring contributing to enhancement in the mechanical properties: (a) in-situ compatibilisation of PP and EPDM and (b) cross-linking in the EPDM phase. Both processes do not only depend on absorbed dose like in traditional electron treatment under static conditions. Moreover, they depend on electron treatment time as well as electron energy. Electron treatment time correlates with dose rate and radical generation rate. Thus we can conclude that radical generation rate of electron induced reactive processing controls structure, morphology and properties of PP-EPDM vulcanisate at fixed mixing rate and fixed mixing temperature range. An influence of reaction rate in relation to mixing rate was already reported by Msakni et al. [20] for cross-linking of ethylene-octene copolymers by peroxide under dynamic conditions.

Further experiments are required to investigate the role of absorbed dose per rotation and electron energy in electron induced reactive processing of PP-EPDM-vulcanisate as well as to understand the mechanism of electron induced reactive processing resulting in the observed experimental data.

\section{Acknowledgements}

K. Naskar is thankful to Alexander von Humboldt Foundation, Germany, for the financial assistance.

\section{References}

[1] Legge N. R., Holden G., Schroeders H. E.: Thermoplastic elastomer: A comprehensive review. Hanser, Munich (1987).

[2] De S. K., Bhowmick A. K.: Thermoplastic elastomers from rubber plastic blends. Horwood, London, (1990).

[3] Gessler A. M., Haslett W. H.: Process for preparing a vulcanised blend of crystalline polypropylene and chlorinated butyl rubber. US Patent 3037954, USA (1962).

[4] Coran A. Y., Patel R. P.: Rubber-thermoplastic compositions. Part I. EPDM-polypropylene thermoplastic vulcanisates. Rubber Chemistry and Technology, 53, 141-150 (1980).

[5] Karger-Kocsis J.: Thermoplastic rubbers via dynamic vulcanisation. in 'Polymer blends and alloys' (eds.: Shonaike G. O., Simon G. P.) Marcel Dekker, New York, 125-153 (1999).

[6] Abdou-Sabet S., Fath M. A.: Thermoplastic elastomer blends of olefin rubber and polyolefin resin. US Patent 4311628, USA (1982).

[7] Abdou-Sabet S., Patel R. P.: Morphology of elastomeric alloys. Rubber Chemistry and Technology, 64, 769-779 (1991).

[8] Ilisch S., Menge H., Radusch H-J.: Vernetzungsausbeute an konventionellen und dynamischen Vulkanisaten. Kautschuk und Gummi Kunststoffe, 53, 206212 (2000). 
[9] Naskar K., Noordermeer J. W. M.: Dynamically vulcanised PP/EPDM blends-effects of different types of peroxides on the properties. Rubber Chemistry and Technology, 76, 1001-1018 (2003).

[10] Naskar K., Noordermeer J. W. M.: Dynamically vulcanized PP/EPDM blends-effects of multifunctional peroxides as crosslinking agents. Rubber Chemistry and Technology, 77, 955-971 (2004).

[11] Naskar K.: Thermoplastic elastomer based on PP/ EPDM blends by Dynamic vulcanization - A review. Rubber Chemistry and Technology, 80, 504-510 (2007).

[12] Chatterjee K., Naskar K.: Development of thermoplastic elastomers based on maleated ethylene propylene rubber (m-EPDM) and polypropylene (PP) by dynamic vulcanisation. Express Polymer Letters, 1, 527-534 (2007).

DOI: $10.3144 /$ expresspolymlett.2007.75

[13] Dole M.: Cross-unking and crystallinity in irradiated polypropylene. Polymer Plastic Technology and Engineering, 13, 41-64 (1979). DOI: $\underline{10.1080 / 03602557908067674}$

[14] Zaharah A. K., Yoshii F., Makuuchi K., Ishikaki I.: Durability of radiation-sterilised polymers: 12 . The effects of nucleating agent on the oxidative degradation of polypropylene. Polymer, 30, 1425-1432 (1989).

DOI: $\underline{10.1016 / 0032-3861(89) 90211-5}$
[15] Yoshii F., Meligi G., Sasaki T., Makuuchi K., Rabei A. M., Nishimato S.: Effects of irradiation on the degradability of polypropylene in the natural environment. Polymer Degradation and Stability, 49, 315321 (1995).

[16] Schulze U., Majumder P. S., Heinrich G., Stephan M., Gohs U.: Electron beam crosslinking of atactic polypropylene: development of a potential novel elastomer. Macromolecular Materials and Engineering, 293, 692-699 (2008).

DOI: $10.1002 /$ mame. 200800093

[17] Majumder P. S., Bhowmick A. K.: Surface and bulk properties of EPDM rubber modified by electron beam irradiation. Radiation Physics and Chemistry, 53, 63-78 (1999).

DOI: 10.1016/S0969-806X(97)00296-X

[18] Majumder P. S., Bhowmick A. K.: Friction behaviour of electron beam modified ethylene propylene diene monomer rubber surface. Wear, 221, 15-23 (1998). DOI: $\underline{\text { 10.1016/S0043-1648(98)00255-5 }}$

[19] Khan M. S., Lehmann D., Heinrich G., Gohs U., Franke R.: Structure-property effects on mechanical, friction and wear properties of electron modified PTFE filled EPDM composite. Express Polymer Letters, 3, 39-48 (2009).

DOI: $10.3144 /$ expresspolymlett.2009.7

[20] Msakni A., Chaumont P., Cassagnau P.: Cross-linking of ethylene-octene copolymers by peroxide under static and dynamic conditions. Polymer Engineering and Science, 46, 1530-1540 (2006).

DOI: $10.1002 /$ pen.20618 